\title{
DESIGN AND IMPLEMENTATION OF A REAL-TIME SLOPE MONITORING SYSTEM BASED ON UBIQUITOUS SENSOR NETWORK
}

\author{
Kyoon-Tai Kim \\ Senior Researcher of Construction Engineering \& \\ Management Research Dept., Korea Institute of \\ Construction Technology, Ph. D. (designated \\ presenter) \\ 2311 daehwa-Dong, Ilsanseo-Gu, Goyang-Si, \\ Gyeonggi-Do 411-712, Korea \\ ktkim@kict.re.kr
}

\author{
Jae-Goo Han \\ Researcher of Construction Engineering \& \\ Management Research Dept., Korea Institute of \\ Construction Technology \\ 2311 daehwa-Dong, Ilsanseo-Gu, Goyang-Si, \\ Gyeonggi-Do 411-712, Korea \\ jghan@kict.re.kr
}

\begin{abstract}
The casualties due to slope failures such as landslide, rock fall, debris flow etc. are about $24 \%$ in total casualties caused by natural disasters for the last 10 years in Korea. And these slope failures in Korea are focused in the season in which typhoon and torrential rain take place. Not much attention, however, have been put into landslide mitigation research. Meanwhile, USN (Ubiquitous Sensor Network) forms the self-organization network, and transfers the information among sensor nodes that have computing technology ability. Accordingly, USN is embossed a social point technology in Korea. Therefore, a lot of study is progressing about practical use of data which was gathered by sensors.

The objective of this paper is to design and implement a real-time slope monitoring system using Ubiquitous Sensor Network (USN) technology. For this we develop module that collects and change slope movement data measured by two tiltmeter and a tension wire, store transferred data in database. Also we develop application program that can easily analyze the data. We apply the prototype system to a test site at KICT for testing and analyzing the system's performance.
\end{abstract}

\section{KEYWORDS}

Ubiquitous Sensor Network (USN), Wireless Sensor Network (WSN), slope failure, monitoring

\section{INTRODUCTION}

\subsection{Background and Objective}

ZigBee is a low-cost, low-power, wireless mesh networking standard which has recently been developed. It is a wireless sensor networking solution that has capable of use for short distance wireless control and monitoring applications. ZigBee is rising up as a new technology that can address the problems of former wired sensor networks. Therefore, various studies have been done on ZigBee in the areas of Ubiquitous Sensor 
Network (USN), Home Networking, and automation both in Korea and in the international scene [1].

Meanwhile, it has been known that the amount of rainfall in 24 hours exceed $20 \%$ of the annual average rainfall could lead to natural disasters.[2] In Korea, over half of the annual average rain falls in the months of July and August. Consequently, natural disasters such as land slides or slope failures occur during these months. Land slides and slope failures have resulted in 318 deaths during the last ten years. This accounts for $24.4 \%$ of the total 1,314 deaths resulting from natural disasters. However, Korea's policies against slope failures center on post-disaster actions and restoration [3]. To prevent such damage from slope failures, there is a need to install various detection sensors in areas prone to slope failure.

The objective of this research is to develop a USN based slope monitoring system that could survey the movements of a slope in danger in real time.

\subsection{Scope and Method of the Research}

The present research will focus on the surface change measurement method out of the many methods for monitoring slope movement because of its high efficiency. In addition, only the tension-wire and the tiltmeter will be considered for the measurement sensors. A USN sensor module integrated with Zigbee communication module will be developed and a prototype monitoring system will be set up and tested at KICT site.

This research will be conducted in the following manner.

First, previous slope measurement sensors and USN technology trends will be investigated and analyzed.

Second, a slope monitoring scenario based on USN will be devised.

Third, a sensor adequate for the devised scenario will be selected. Then, the selected sensor along with a ZigBee communication module adequate for the scenario will bes developed.

Fourth, prototype slope monitoring system based on USN will be set up.
Fifth, the validity of the system will be verified through on-site experiments.

\section{TRENDS OF RELATED TECHNOLOGIES}

\subsection{Trends in Slope monitoring techniques}

Slope policies can be largely categorized into two fields: protection and reinforcement. Protection policies focus on slopes which are currently stable. The policies concentrate on protecting the slopes so that they remain stable during rainy season or weathering processes. Major protection policies include rock netting, rock fences, retaining walls, seed spray, and drainage pipes. Reinforcement policies refer to activities that try to increase the forces available to resist movement or decrease the forces driving movement. Major policies include cut slopes, anchoring, and segmental retaining walls [4].

An aggressive method for slope collapse is to accurately know of slopes that are vulnerable to collapse and to protect and mitigate so that slope collapse does not occur. In order to predict such slope collapses, it is important to observe the movements on the surface of the slopes and research the factors that cause such movements. Measurements could be used as raw data.

\subsection{USN Technology Trend}

USN (Ubiquitous Sensor Network) means 'to attach sensors (electronic tags) to anywhere that is necessary so that a object's information and its surrounding information (such as temperature, humidity, pollution, cracking) could be detected and such information is connected to a network and maintained in real time' [5]. Ultimately, this means that computing and communication functions can be deployed to virtually all objects and therefore an 'anywhere, any time' communication environment could be made possible. In Korea, USN is being currently tested in various fields such as smart homes, distribution industry, ITS, health care, national defense, environment, robots, automation, and factory automation.

ZigBee is a close-range wireless communication technology that is utilized in USN. ZigBee is highly energy efficient in that it could last for months on 
two AA-size batteries. It can also be used to set up $10 \sim 10,000$ sensor networks. In addition, ZigBee can construct ad-hoc networks and so has the advantage over Bluetooth in that it could establish a wider PAN (Personal Area Network) [6].

\section{DEVELOPMENT OF USN-BASED SLOPE MONITORING SCENARIO}

In this chapter, the limitations of existing systems were analyzed and then based on that data, a scenario of a USN-based system was devised.

\subsection{Limitations of Existing Systems}

The following is a brief summary of the setting up of existing wired systems: 1) preparation, 2) sensor installation, 3) installation of communication and power lines, 4) power connection and testing, and 5) completion. During set up, at stage 2) sensor installation and stage 3) installation of communication and power lines, the jobs are done right at the slope. However, since the slope monitoring systems are installed in places where collapse or movement is expected, most of the slopes for installation are steep and it is difficult to secure the area for installation. Therefore, the danger of accident at the installation site is high and work efficiency has declined much.

After the installation of the system, there are cases that either the communication or power lines are cut due to falling stones or wild animals. In these cases, the sensors located around the cut area do not function at all. What is more, the installation sites of the monitoring systems are scattered all throughout Korea. Therefore, neither restoration nor maintenance of the network systems is easy.

\subsection{Devising of the Monitoring Scenario}

The following is the flow for the data collection of the slope collapse monitoring system. First of all, the sensors should be installed at slope sites in danger of collapse or where some possibility of movement is exist. If movements such as translation, rotation, or settlement occur at the slope surface, the tension wire and the tiltmeter should detect such movements. The movement data detected by the sensors is collected into a data log via ZigBee wireless communication network. The collected data is then sent to the control room through CDMA network. The schematized flow is shown in Figure 1.

If a sensor network that could actualize the flow stated above is installed and activated at the slope site, then the sensing periods and the management limit could be adjusted freely by remote. The manager could control the periods according to rainfall and surface status. When the periods are controlled, then the sensor nodes automatically wake up at the set periods, senses the necessary data, relays the data and then goes back to sleep mode. This minimizes battery use.

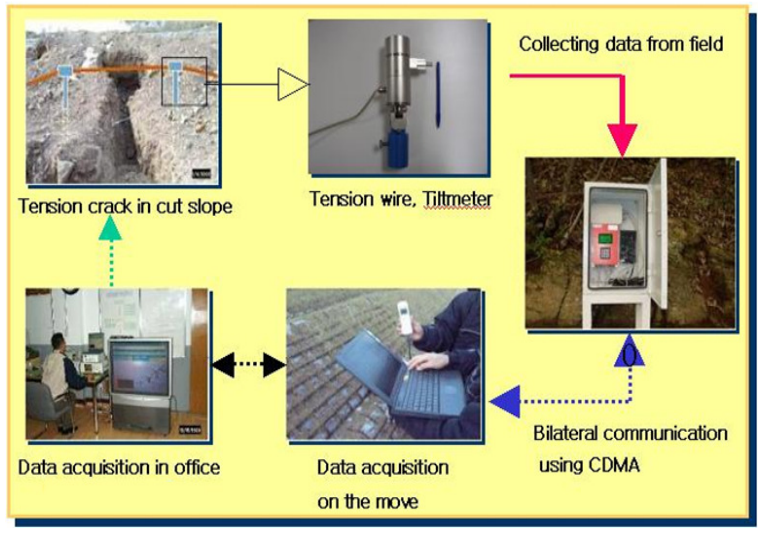

Figure 1. Flow Chart of Slope Collapse Monitoring

ZigBee technology was used for the communication between the sensor and sink nodes and between the sink nodes and the gateway. This is because the network that consists of the sensor nodes, sink nodes, and the gateway is a network installed at the slope, a relatively limited range. For the communication between the gateway and the control center, the CDMA network is used because only one control center should be located in the entire nation.

Finally, if an abnormal movement occurs at the slope, a text message (SMS; Short Message Service) is sent to the manager's mobile phone and a warning beep goes off at the server at the control center. The schematization of these concepts is shown in Figure 2. 


\section{SENSOR SELECTION AND DEVELOPMENT OF COMMUNICATION MODULE}

\subsection{Sensor Selection}

As stated above, the present research focuses on surface change measurement. Generally, tensionwires and tiltmeters are used for surface change measurement so these two measuring instruments were used for this research. In this research, the TTW sensor, which has already been utilized in Korea's wired-based slope measurements, was selected. A TTW sensor consists of a tension-wire and two tiltmeters on the $\mathrm{X}$ and $\mathrm{Y}$ axis. It is shown in Figure 3. Specifications for the TTW sensor are shown in Table 1.

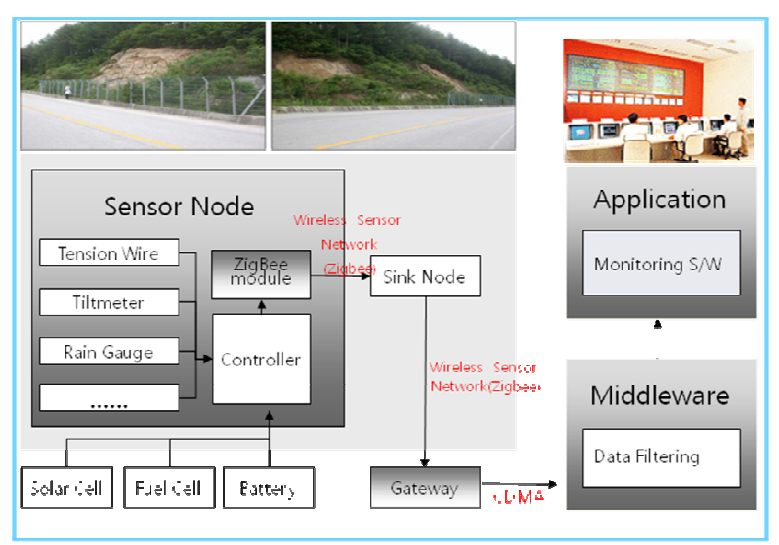

Figure 2. Conceptual Map of Monitoring Scenario

\subsection{Development of Sensor Node}

Generally, in order to make a sensor node, three modules are needed. First, a sensor or sensors which detect object's status data, Second, ZigBee communication module which make possible to communicate other node, Third, an interface module which convert the analog signal from the sensor to a digital signal.

The concept of the sensor node used for this research is shown in Figure 4 and its specification is shown in Table 2. The sensor node produced according to the specifications mentioned above is shown in Figure 5(a). Figure 5(b) is shown the gateway.
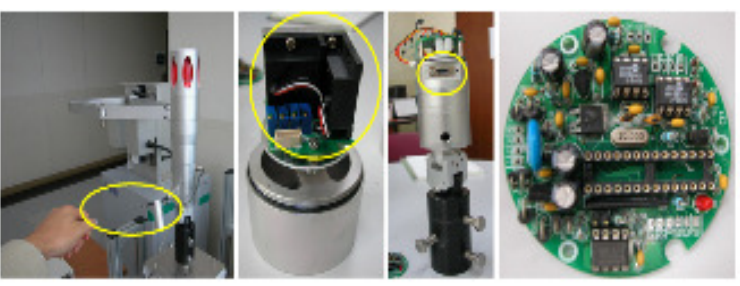

(a) Tension-wire (b) Tiltmters (c)RS-485 (d) Sensor

Figure 3. TTW Sensor

Controller

Table 1. Specification of TTW Sensor

\begin{tabular}{|c|c|}
\hline \multicolumn{2}{|l|}{ Tension wire } \\
\hline Measurement Range & $\pm 200 \mathrm{~mm}$ \\
\hline Linearity & $\pm 0.1 \%$ Full Scale \\
\hline Sensing Device & Precision Potentiometer \\
\hline Repeatability & $\pm 0.01 \%$ Full Scale \\
\hline Construction & $\begin{array}{l}\text { Anodized Aluminum Body \& } \\
\text { Polyethylene Holder }\end{array}$ \\
\hline Wire Rope & Pi $0.8 \mathrm{~mm}$ Stainless Steel \\
\hline Wire Rope Tension & $30 \mathrm{~N}$ min \\
\hline Operating Temperature & $-30^{\circ} \mathrm{C}$ to $75^{\circ} \mathrm{C}$ \\
\hline Excitation Voltage & 9VDC $\min$ to $28 \mathrm{VDC} \max$ \\
\hline Out & $\begin{array}{l}\text { RS422/485, 19200bps, } \\
\text { Decimal Out }\end{array}$ \\
\hline \multicolumn{2}{|l|}{ tiltmeter } \\
\hline Total Range & $\pm 30^{\circ}$ \\
\hline Linear Range & $\pm 20^{\circ}$ \\
\hline Threshold & $0.01^{\circ}$ \\
\hline $\begin{array}{l}\text { Linearity: } \\
\cdot \text { Null to } 10^{\circ} \\
\cdot 10^{\circ} \text { to } 20^{\circ} \\
\cdot 20^{\circ} \text { to } 30^{\circ}\end{array}$ & $\begin{array}{c} \pm 0.1^{\circ} \\
\quad \pm 1 \% \\
\text { Monotonic } \\
\end{array}$ \\
\hline Sensing Device & Precision Clinometer \\
\hline Repeatability & $\pm 0.05^{\circ}$ \\
\hline $\begin{array}{l}\text { Temperature Coefficient: } \\
\text { - Null } \\
\text {-Scale Factor }\end{array}$ & $\begin{array}{l}0.01 \%{ }^{\circ} \mathrm{C} \\
0.1 \% /{ }^{\circ} \mathrm{C}\end{array}$ \\
\hline Excitation Voltage & 9VDC min to $28 \mathrm{VDC} \max$ \\
\hline Excitation Current & $5 \mathrm{~mA}$ \\
\hline
\end{tabular}




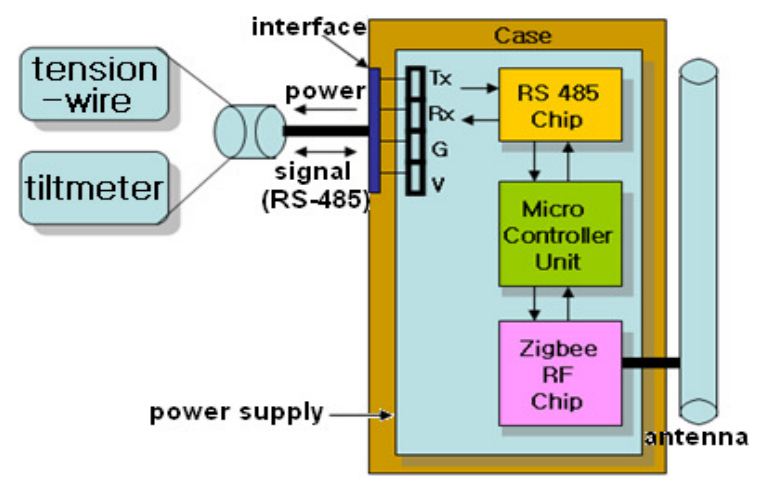

Figure 4. Sensor Node Configuration

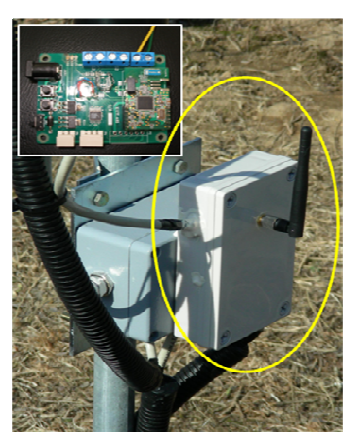

(a) Sensor node

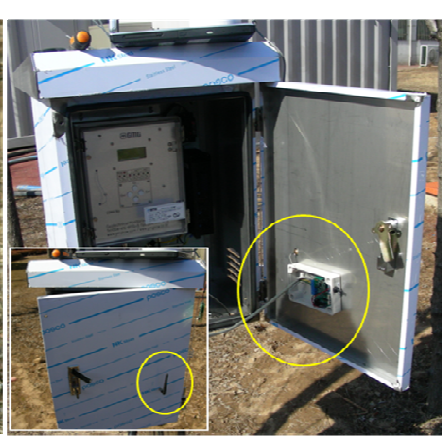

(b) Gateway

Figure 5. Sensor Node and Gateway

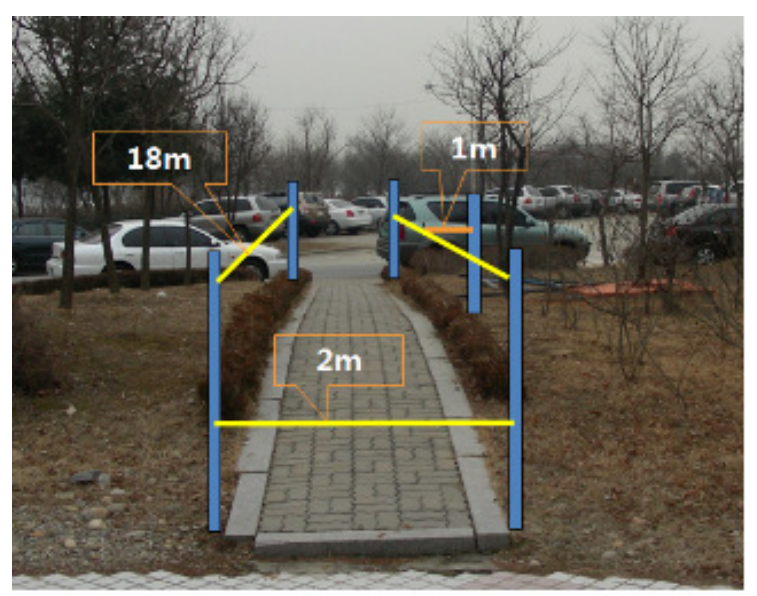

Figure 6. Testbed within KICT
Table 2. Specification of ZigBee Communication Module

\begin{tabular}{c|l}
\hline Type & \multicolumn{1}{|c}{ Specification } \\
\hline Chipset & Zigbee Alliance Certified Chipset \\
\hline Frequency & $2.4 \mathrm{GHz}$ \\
\hline Operating Voltage & $2.2 \sim 3.6 \mathrm{~V}$ \\
\hline Interface & $\mathrm{RS}-485$ Interface \\
\hline $\begin{array}{c}\text { Communication } \\
\text { Channels }\end{array}$ & $16 \mathrm{CH}$ \\
\hline OS & Nano-Qplus \\
\hline Distanceforwireless & $50 \sim 100 \mathrm{~m}$ (open space) \\
\hline Antenna & Dipole Antenna \\
\hline Power consumed & $\begin{array}{c}\text { RX: below } 500 \mathrm{~mA}, \mathrm{TX}: \text { below } 70 \mathrm{~mA}, \text { In } \\
\text { sleep mode : below 5 mA }\end{array}$ \\
\hline
\end{tabular}

\section{SETTING UP OF THE PROTOTYPE SYSTEM AND VERIFICATION OF THE SYSTEM'S VALIDITY}

In this research, a testbed for the prototype slope monitoring system based on USN was set up at KICT site and the system's adequacy was tested in actual conditions.

\subsection{Setting up of the Prototype System}

The prototype system was installed test site where is within the grounds of the Korea Institute of Construction Technology (KICT). Table 3 shows the summary of the testbed and Figure 6 shows the test site.

As the application for the server of control center, commercialized software was used in the system design and manufacturing stage. However, the commercial products were customized so that they could perform the functions of the devised scenario.

\subsection{On-site Adaptability Test}

The collection and analysis of the transferred data of the above tests are shown in Figure 7 and Figure 8. Figure 7 shows the data values of the tension wire on a graph. Figure 8 shows the data values of the tiltmeters on a graph. Each TTW sensor has two tiltmeters, therefore, the data of each individual sensor can be confirmed. 
Table 3. Outline of Testbed

\begin{tabular}{|c|c|}
\hline Location & - test site at $\mathrm{KICT}$ \\
\hline Objectives & $\begin{array}{l}\text { Verification of the stability of } \\
\text { communication and reliability of data } \\
\text { transfer between sensor node and gateway } \\
\text {. Adaptability test (corrosion, battery } \\
\text { development, etc.) }\end{array}$ \\
\hline Period & $\cdot 2007.3 .1 \sim 9.30$ (7 months) \\
\hline $\begin{array}{c}\text { System } \\
\text { Compo- } \\
\text { sition }\end{array}$ & $\begin{array}{l}\cdot 8 \text { TTW sensors } \\
\cdot \text { 1 gateway(data logger, CDMA modem) } \\
\cdot \text { - } 9 \text { ZigBee Communication modules } \\
\text { - Control center: } 1 \text { desktop and } 1 \text { laptop } \\
\text { computers (APP, CDMA modem) }\end{array}$ \\
\hline
\end{tabular}

Looking at the test results, we could not find any major problems in the operation of the USN-based slope monitoring test system. However, if the test system that we developed is to be implemented in actual slope sites, then we think there are some improvements that should be made to the system. For example, the frequency range of the ZigBee is very strong in linearity. Therefore, if the sensors are to be installed in radio wave shadow zones, then there may be problems in communication.

\section{CONCLUSION}

The objective of the this research was to apply USN technology to existing wired-base measuring systems thereby setting up a USN-based slope collapse monitoring system that makes real-time measurement possible. Then, the system was verified through on-site adaptability tests. To achieve this objective, first, existing slope measurement conditions were investigated and analyzed and a sensor was selected based on the analysis. Second, concerning the selected sensor, a scenario for the sensor module, sensor node, gateway, and application was devised. Based on the scenario, a system was designed and developed and then a test system was set up. Third, an on-site adaptability test of the set up prototype system was carried on for 7 months. As a result, we found no major problems in operating the system until the present.
The system developed in this research is a prototype at stage 1 . Therefore, a system development at stage 2 is necessary for commercialization of the system. In other words, there is a need to address the limitations of the stage 1 prototype such as power supply by Solar Cells and addition of a rain gauge and so on.

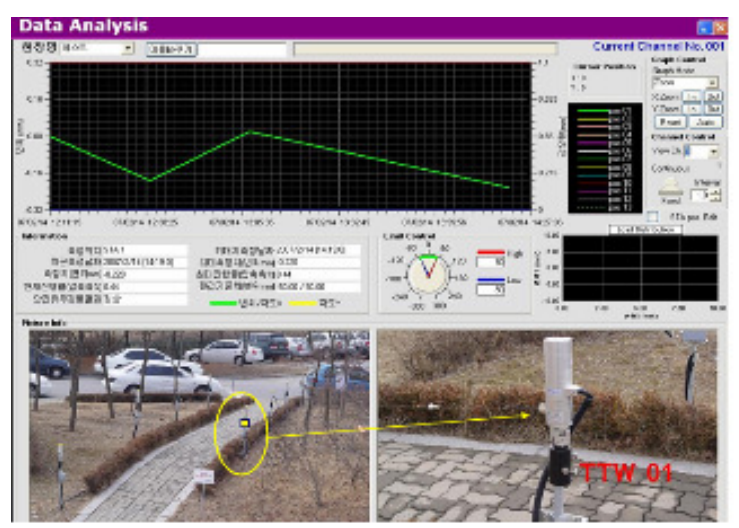

Figure 7. Data collected by tension-wire (Source : Han, Jae-goo 2007)

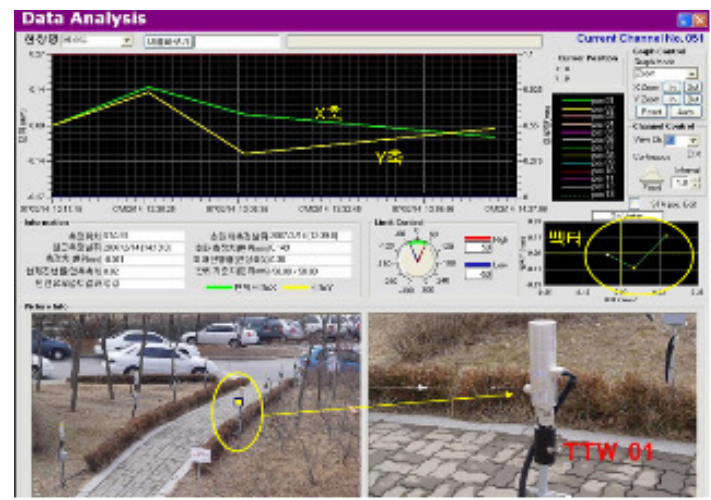

Figure 8 . Data collected by two tiltmeters (Source : Han, Jae-goo 2007)

\section{REFERENCES}

[1] Han, Jae-goo and Kim, Kyoon-Tai (2007) Development of a Prototype System for Slope Failure Monitoring Based on USN Technology, Korea Institute of Construction Engineering and Management Conference Proceeding, Korea Institute of Construction Engineering and Management, 11. 
[2] Olivier, M. Bell, F. G. Jerry, C. A., (1994)The Effect of Rainfall on Slope Failure, with Examples from The Greater Durbar Area, Proceedings of 7th intern. Vong. IAEG.

[3] National Institute for Disaster Prevention, (2004) A Study on Detection and Observation of Slope Failure, National Emergency Management Agency, 12.

[4] Korea Institute of Construction Technology (2006) Development and Operation of Cut Slope Management System in 2005, Ministry of Construction and Transportation, 4.

[5] Nam, Sang-yeop et,.al. (2006) Ubiquitous Sensor Network, Sanghakdang Publishing Co., Ltd , 11

[6] Telematics USN Research Center (2006) U-sensor Network Structure Specification, Electronics and Telecommunications Research Institute, 6. 